\title{
Early Operative Treatment for an Enterocutaneous Fistula afier Gunshot Wound
}

\section{JUR}

\author{
Agron Dogjani' ${ }^{1}$ Blenarda Hasanaj', Matevossian E' ${ }^{2}$ Dietrich Doll ${ }^{3}$, Rifat Latiff ${ }^{4}$ \\ 'National Trauma Center, University Hospital of Trauma, Tirana, Albania; ${ }^{2}$ Department \\ of Surgery, Klinikum rechts der Isar der TU Muenchen; Munich, Germany; ${ }^{3}$ Honorary \\ Trauma Lecturer, University of the Witwatersrand, Johannesburg, South Africa; \\ ${ }^{4}$ Department of Surgery, University of Arizona, Tucson, Arizona, USA.
}

Abstract:

Introduction: The successful treatment of an enterocutaneous fistula (ECF) is challenging even for experienced surgeons, as it is associated with potential complications such as infection, abdominal sepsis, dys-electrolytemia, septic shock and malnutrition. All of these conditions may congregate and lead to increased mortality in these patients in addition to the original trauma. Case Report: We describe a 27-year old male who was shot in the left thoraco-abdominal region without an exit wound. On laparotomy, multiple injuries to jejunum, ileum and sigmoid were identified. Primary repair of sigmoid, end-to-end jejunostomy and end-to-end ileostomy was performed. On postoperative day 10, an ECF erupted as a low output fistula ( $100 \mathrm{ml} / 24 \mathrm{~h})$. The patient was put on full parenteral treatment. Following work up including CT scan and fistulogram, the patient was taken back to the operating room for washout and diverting ileostomy with fistula tract resection. He fully recovered uneventfully following this second operation. Conclusion: Early surgical treatment may work out advantageously compared to possible conservative treatment in low output fistulas following a gunshot of the thoraco-abdominal region.

Key words: Angiography, Fistula, lleostomy, Multiple Trauma, Shock.

\section{Introduction}

Enterocutaneous fistulas are dangerous and rarely encountered complications associated with abdominal surgery that may result in increased morbidity and mortality [1]. The treatment of enterocutaneous fistulas is particularly challenging, as surgeons must be cautious of dyselectrolytemia, septic shock, and malnutrition which may add to the primary trauma and its effects on morbidity and mortality [2]. The earliest record of an enterocutaneous fistula can be found in the Bible, Old Testament, in the book of Samuel, which is said to be timed between 1043 BC and 1004 BC [3]. Celsus first described the first attempt to surgical repair of a colo-cutaneous fistula. During the $18^{\text {th }}$ century, John Hunter defended a conservative treatment technique reported that, in some cases that these fistulas have closed spontaneously [4-7]. Factors for an "easier" fistula closure are low output

\section{Corresponding Author: Dr. Dietrich Doll}

Email: dolld@gmx.de

Received: August 26, 2015 | Accepted: November 24, 2015 | Published Online: December 25, 2015

This is an Open Access article distributed under the terms of the Creative Commons Attribution License (creativecommons.org/licenses/by/3.0)

Conflict of interest: None declared | Source of funding: Nil | DOl: http://dx.doi.org/10.17659/01.2015.0141 
fistula, a long fistula tract, the absence of carcinoma and obstruction. Caloric hyperalimentation before surgery has been proven to be of paramount importance before surgery. Closure rates up to $70 \%$ with mortality rates coming down to $6 \%$ were reported. This marked the milestone approach of EC fistula care that started with $7 \%$ healing rate and $97 \%$ mortality with inadequate nutrition, as reported by Chapman et al. [7].

EC after penetrating trauma to the abdomen is a relatively new region of interest, with young patients and a short history of disease. As such, hyperalimentation preceding surgery is not needed. In this patient we acted identifying a non-malnutrition situation and opted for immediate surgical approach.

\section{Case Report}

The patient was brought to our hospital by alleged history of single gunshot in the left thoracoabdominal region 1 hour before. There was no exit wound detectable on clinical examination.

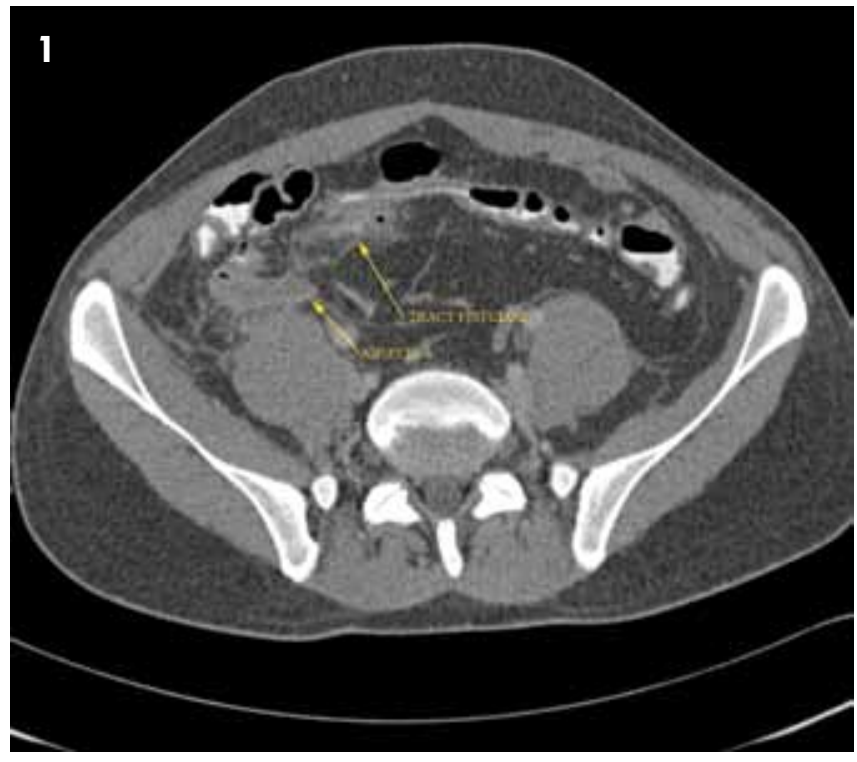

The patient was hemodynamically stable. The abdominal X-ray revealed that bullet was lodged in the small pelvis close to the right acetabulum. Thus, the patient was swiftly taken to the operating room. On operation, large amount of jejunal and colonic contaminations were present within the abdomen, which were flushed out. The bullet had caused multiple perforations to the ileum, jejunum and sigmoid colon. The spleen was uninjured, as was the thoracic cave. No pelvic vascular lesion was present. A jejunal resection with end-to-end anastomosis $100 \mathrm{~cm}$ from the ligament of Treitz was performed, followed by an ileal segmental resection $70 \mathrm{~cm}$ from the ileocoecal valve (endto-end anastomosis). Primary closure of the single hole in the sigmoid colon was judged feasible and was done. Post-operatively the patient recovered clinically on day 8 , when he manifested a sigmoidocutaneous secretion (enterocutaneous fistula). A CT scan with double contrast was performed, which demonstrated a leak of contrast to the skin. Additionally, there were multiple abscesses present between the intestinal loops, within the left subphrenic space, in the sub-hepatic area as well as in the retro-cecal area [Fig.1,2].

A fistulogram confirmed a fistula channel of about $20 \mathrm{~cm}$ length [Fig.3-5]. In these conditions we

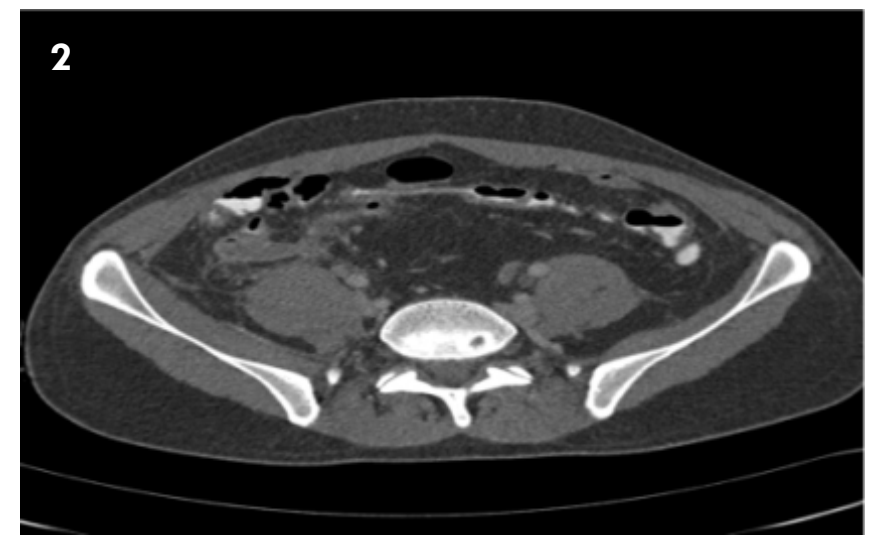

Fig.1,2: CECT abdomen showing contrast leak, multiple abscesses present between the intestinal loops, left sub-phrenic space, sub-hepatic area and retro-cecal area. 

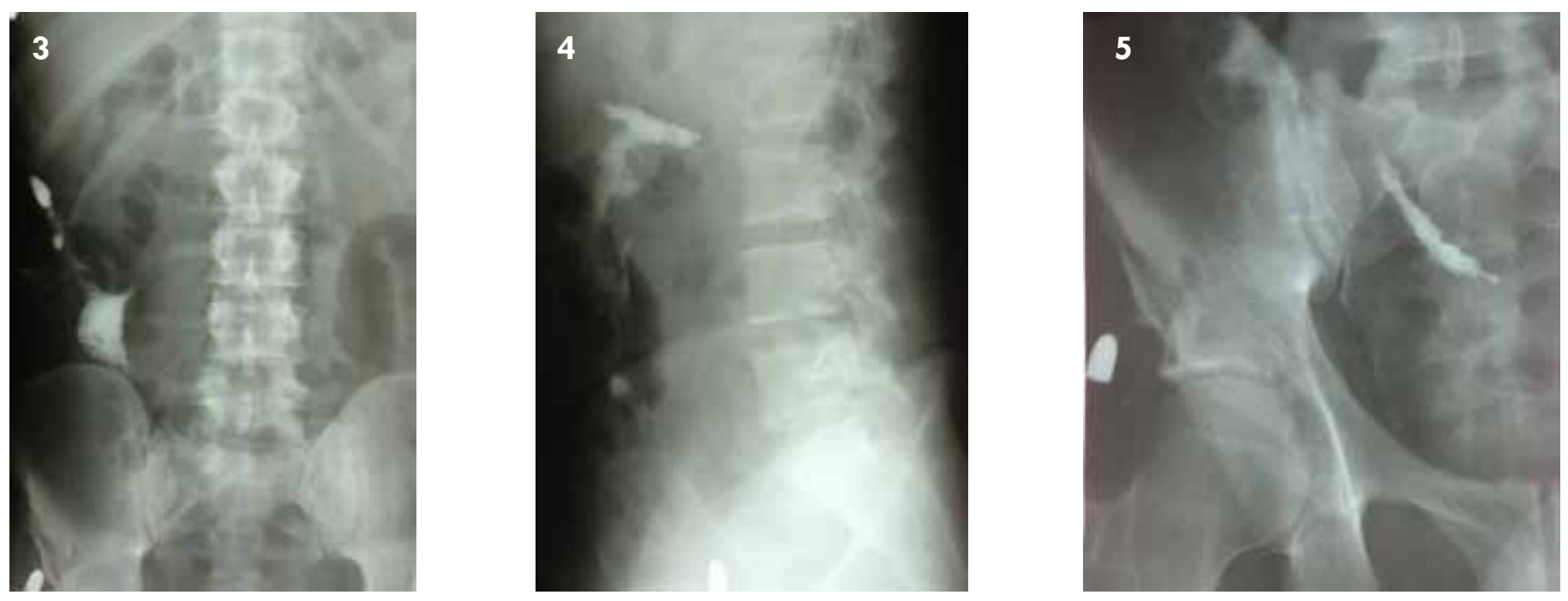

Fig.3,4,5: Fistulogram confirming a fistula channel of about $20 \mathrm{~cm}$ length.

re-explored the patient. He was taken back to the operating room for thorough abdominal washout. No further bowel injury could be detected. The sigmoid fistula was resected, and the sigma fistulaostomy carefully debrided and closed primarily again. A temporary diverting ileostomy was fashioned in the right lower quadrant. Postoperative course was uneventful, and the patient was discharged after five days of hospitalization.

\section{Discussion}

Entero-cutaneous fistulas are one of the most feared and catastrophic complications following abdominal surgery, especially in the old and very sick patients. Their metabolic situation is typically not well equilibrated, their nutritional status may be compromised, and concomitant diseases as well as medication needed may hamper wound healing and recovery. It is thus imperative to initiate a most efficient treatment when EC fistula has been seen, which depends on a majority of factors. It is now best practice to treat any signs of malnourishment before any surgical procedure is undertaken in these patients. A proper and fast recovery is bound to fail if low albumin levels and chronic infection delay wound healing. Chapmans priorities consist of 4 phases as follows [7]: Phase 1: management of dehydration, sepsis, and fistula secretion fluids; Phase 2: initiation of electrolyte replacement and intravenous nutrition; Phase 3: institution of enteral feeding access and continued vigilance in the search for uncontrolled sepsis; Phase 4: major surgical intervention.

The understanding of EC fistula pathophysiology has lead to further subclassifications in terms of fistula length, fistula volume output and severity of nutritional imbalance [8-9] but surgery has had its' place always after feeding and nutritional needs were corrected. During long times of phase 1 to phase 3 , substantial proportions of fistula subsided, thus conservative treatment was postulated to be superior to surgical treatment. It took years to differentiate what treatment modality is most beneficial for the individual patient, as conservative treatment is not always possible or advantageous (e.g. in high output ECF), as it may be associated with serious complications $[4,5]$. Shaikh et al. conducted a retrospective study of 213 patients who had received treatment for post-operative entero- 
cutaneous fistulae during 2001-2008 [6]. They concluded that high output fistulae are not likely to close on their own and that early intervention surgery proved to be lifesaving for such patients. With advancement in treatment modalities and a more individualized treatment approach, mortality due to EC fistula has decreased to $5 \%-25 \%$ within the second half of the last century [10-13].

Septic complications have adverse outcomes and should be corrected before surgery $[14,15]$. A 24-hourly fistula output over $500 \mathrm{ml}$ was shown to ameliorate the patients situation after surgery and was associated to a higher fistula recurrence, thus distal bowel obstruction relief was of paramount importance in these patients. It was and is not always easy to correct any bowel obstruction in an abdomen where adhesions have created bowel blocks which are almost impossible to separate without injuring new adjacent bowel segments. This could create new fistula. Thus the insertion of foreign materials into the fistuli was tested, using vicryl mesh or vicryl plugs. Gelatine sponges, Histoacryl glue and biodegraded porcine pigs were applied, but with varying degrees of success. Even denaturation with phenol has been thought of, but as in perianal fistuli and pilonidal sinus disease, these approaches have not been shown to be of benefit. Surgically speaking, several devices have been proposed to close the fistuli; these were wooden and metal buttons to be inserted into the fistula to stop the outflow [16,17]. Also externalization of the fistula has been proposed. When direct suture may repeatedly fail to heal, interposition of well perfused and immunocompetent tissue has been the most promising approach, as with muscle flaps or omentum flaps. These interposition flaps are not always possible though, as repeat abdominal surgery in a septic abdomen may have used up the omentum, or it may be resected or stuck to adjacent organs. Especially in situations with tense intra-abdominal adhesions, the source of the bowel leak may be difficult to expose and to close without undue tension.

As small bowel secretions have toxic effects onto the skin, silicone polymer gels may protect the skin around the cutaneous fistuli openings, as they may protect the skin around a stoma if needed. Continuous suction devices (negative wound pressure dressings) have been gaining ground in desperate cases with large EC fistulas. They suction away large amount of aggressive fluids, but fluid and electrolyte replacement have to be kept in mind, as skin protection for the larger area covered with the opsite plastic sheet [18-21]. A special danger arises if a negative suction dressing is placed into the abdomen onto the bowel resulting in new fistuli when being kept under direct suction contact. If a plastic sheet or a silicone sheet layer separate bowels and suction dressing, low pressure suction will not harm the bowel. The suction devices enable better and easier wound care, and they buy time for the fistula to close, but they keep sucking at the fistula channel.

Enterocutaneous fistulas remain a challenge for the treating surgeon. He needs to know and to work the key decision elements to set the time and decision for the conservative strategy versus surgery [18-19]. Numerous aspects from nutritional status, immune function, and duration of insults have to be well known to guarantee best care for our patients with an EC fistula.

\section{Conclusion}

Whereas correction of malnutrition, immunocompromise and sepsis remain the mainstay in the weak old patient, early surgical treatment remains the mainstay of treatment in young patients with entero-cutaneous fistulas resulting from penetrating trauma. There is still a substantial challenge in the patient with laparostoma and EC fistula to get the bowel leak closed. 


\section{References}

1. Edmunds LH Jr, Williams GM, Weleh CF. External fistulae arising from gastro-intestinal tract. Ann Surg. 1960;152:445-471.

2. Hollington P, Mawdsley J, Lim W, Gabe SM, Forbes A, Windsor AJ. An 11 -year experience of entero-cutaneous fistula. BJS. 2004;91:16461651 .

3. Martinez JL, Luque-de-Leon E, Mier J, Blanko Benavides, Robledo F. Systematic management of post-operative enterocutaneous fistulae: Factors related to outcome. World J Surg. 2008;32:436-443.

4. West MA. Conservative and operative management of gastrointestinal fistulae in critically ill patients. Curr Opin Crit Care. 2000;6: 143-147.

5. Evenson AR, Fischer JE. Current management of enterocutaneous fistula. J Gastrointestinal Surg 2006; 10:445-446.

6. Shaikh IA, Ballard-Wilson A, Yalamarthi S, Amin Al. Use of topical negative pressure in assisted abdominal closure does not lead to high incidence of enteric fistulae. Colorectal Dis. 2010;1 2:931-934.

7. Chapman R, Foran R, Dunphy JE. Management of intestinal fistulas. Am J Surg. 1964;108:157164.

8. Rolstad BS, Bryant R. Management of drain sites and fistulas. In: Bryant R (ed.), Acute and Chronic Wounds. St. Louis: Mosby. 2000:317-341.

9. Kozell K, Martins L. Managing the challenges of Enterocutaeous. Availabe at: http://cawc.net/ images/uploads/wcc/Kozell.pdf Accessed on August 26,2015.

10. Lynch AC, Delaney CP, Senagore AJ, Connor JT, Remzi FH, Fazio VW. Clinical outcome and factors predictive of recurrence after entero-cutaneous fistula surgery. Ann Surg. 2004;240:825-831.
11. Schein M, Decker G. Gastro-intestinal fistula associated with large abdominal defects: experience with 43 patients. $\mathrm{Br} J$ Surg. 1990;77:97-100.

12. Schein $M$, Decker GA. Post-operative external alimentary tract fistulae. Am J Surg. 1999; 161:435-438.

13. Blackett RL, Hill GL. Post-operative external small bowel fistulae: A study of a consecutive series of patients treated with intravenous hyperalimentation. $\mathrm{Br} J$ Surg. 1978;65:775778.

14. Makhdoom ZA, Komar MJ, Still CD. Nutrition and enterocutaneous fistula. J Clin Gastroenterol. 2000;31:195-204.

15. Craig LA, Conor PD, Anthony JS, Jason TC, Feza HR, Victor WF. Clinical Outcome and factors predictive of recurrence after entero-cutaneous fistula surgery. Ann Surg. 2004; 240:825-831.

16. Joseph EG. High intestinal fistula and its treatment by the use of a Pauls tube. Am J Surg. 1948;75(4):640-642.

17. Mayo $\mathrm{CH}$. Enterostomy and the use of the omentum in the prevention and healing of fistula. Ann Surg. 1917;66(5):568-570.

18. Li J, Ren J, Zhu W, Yin L, Han J. Management of enterocutaneous fistulae: 30-year clinical experience. ChinMed J(Engl). 2003;1 16(2):171 175.

19. Galie KL, Whitlow CB. Post-operative enterocutaneous fistula: When to re-operate and how to succeed. Clin Colon Rectal Surg. 2006; 19(4):237-243.

20. Kaur N. Improving outcome in patients with high out put small bowel fistula. Trop Gastroenterol. 2004;25(2):92-95.

21. MacFadyen BV Jr, Dudrick SJ, Ruberg RL. Management of gastrointestinal fistulas with parenteral hyperalimentation. Surgery. 1973;74(1):100-105. 